\title{
Do Public Consultations Reduce Blame Attribution? The Impact of Consultation Characteristics, Gender, and Gender Attitudes
}

\author{
Anthony Kevins ${ }^{1}$ D $\cdot$ Barbara Vis $^{2}$ iD
}

Accepted: 19 September 2021

(c) The Author(s) 2021

\begin{abstract}
Can public consultations - gatherings organised to solicit constituent opinionsreduce the blame attributed to elected representatives whose decisions end up backfiring? Using two pre-registered survey experiments conducted on nationally representative samples of US respondents, we examine whether the effectiveness of consultations as a blame avoidance tool may be shaped by: (1) consultation characteristics, especially regarding whether or not representatives align their policies, either actively or passively, with constituent opinion; and (2) elected representative and constituent characteristics, especially regarding a representative's gender and constituents' gender attitudes. Results suggest that public consultations are indeed liable to decrease blame attribution, just so long as constituent opinion is not explicitly opposed to the representative's decision. Active alignment with constituent opinion, however, does not appear to be a requirement for decreased blame attribution-and effects related to gender and gender attitudes are also largely absent. These findings are important for scholars seeking to better understand blame attribution, clarifying how public consultations might help politicians to pre-empt blame by reducing clarity of responsibility.
\end{abstract}

Keywords Blame avoidance $\cdot$ Public consultations · Gender · Hostile sexism · Clarity of responsibility

Anthony Kevins

a.kevins@lboro.ac.uk

Barbara Vis

b.vis@uu.nl

1 School of Social Sciences and Humanities, Loughborough University, Loughborough, UK

2 Utrecht University School of Governance, Utrecht University, Utrecht, The Netherlands 
Problem solving is an essential part of governance. When faced with a problem, however, elected representatives must regularly make decisions that could have negative consequences for others and, by ricochet, for their own electoral careers.

How might elected representatives find a way out of this dilemma? One solution is to try to pre-empt blame by bringing other actors (e.g. opposition parties, experts, voters) into the decision-making process (e.g. DeScioli \& Bokemper, 2014). We argue that holding a public consultation-i.e. a gathering organised to solicit constituents' opinions - is a particularly promising tool to do so. Two logics underlie this argument. First, public consultations may diffuse responsibility by adding constituents into the chain that connects representatives to policy consequences (Malle et al., 2014). The mechanism here is a weakened clarity of responsibility (e.g. Hobolt et al., 2013). Second, we know from the literature on procedural fairness that simply hearing constituents out at a public consultation-irrespective of the decision that is ultimately reached-can increase perceived democratic responsiveness and possibly even decision acceptance among participants and the general public (see Esaiasson et al., 2017 and 2019 for a discussion). Insofar as these factors are themselves tied to blame attribution, public consultations may be a promising anticipatory blame avoidance strategy (i.e. a strategy that precedes the emergence of blame and aims to prevent the blame for occurring or facilitate handling its consequences; see Hinterleitner \& Sager, 2016). To date, however, there is no work that investigates these links.

We thus set out to examine whether public consultations may obscure blame attribution, paying particular attention to how this potential relationship might be shaped by (1) consultation characteristics and (2) elected representative and constituent characteristics. In the first instance, we draw insights from research on clarity of responsibility and procedural fairness to assess the potential importance of whether representatives align their policies, either actively or passively, with constituent opinion. In the second, we build on literature suggesting that legislators' personal characteristics can shape how the public reacts both to them as individuals and to the proposals they put forth (e.g. Carey \& Lizotte, 2019; Kevins \& Robison, 2021). Gender and gender attitudes have attracted particular attention for their potential to shape reactions to scandals and controversies (e.g. Bauer et al., 2017; Eggers et al., 2018; Pereira, 2020), yet research on clarity of responsibility, procedural fairness, and blame avoidance have generally ignored their potential impact. We therefore explore whether and to what extent an elected representative's gender and constituents' gender attitudes impact the effectiveness of public consultations as a blame avoidance tool.

Our analysis is based on two pre-registered survey experiments conducted on nationally representative samples of US respondents: one centred on a cold snap in the wake of cuts to homeless shelter funding $(n=3200$; quota sample with Lucid); and the other centred on damage prevention efforts in the face of an impending flood ( $n=2299$; quota sample with Qualtrics). The results show that public consultations may indeed decrease blame attribution. However, this effect is only visible where constituent opinion is not opposed to the elected representative's decision-i.e. in cases where either (a) the public supported the representative's initial proposal or (b) the representative adapted the initial proposal to align with constituent opinion. 
Gender-related effects, in turn, are largely absent-suggesting that these dynamics play out similarly for male and female representatives. These findings are important for those seeking to better understand blame attribution, clarifying how public consultations might help politicians to pre-empt blame by reducing clarity of responsibility.

\section{Background}

\section{Public Consultation Characteristics}

Drawing insights from the literature on clarity of responsibility (e.g. Anderson, 2007; Powell et al., 1993), this study starts from the claim that the clearer the potential attribution of responsibility is, the easier it will be for voters to apportion blame (i.e. 'a "bad" or "wrong" thing to a particular person or entity' (Sulitzeanu-Kenan \& Hood, 2005, p. 1)). As a consequence, voters should be more likely to concentrate blame on a single representative whenever clarity of responsibility is relatively high. Key here is the length of, and the number of other actors involved in, the causal decision path linking a representative to a negative consequence (Malle et al., 2014). All else being equal, we would expect a larger number of intermediate links to be associated with a decrease in causal attribution (e.g. Hobolt \& Tilley, 2014; Wolff, 2003). Experimental research from DeScioli and Bokemper (2014) provides some support for this general relationship, while observational studies underscore the correlation between clarity of responsibility and blame attribution (e.g. Oktay, 2018; Wlezien \& Soroka, 2011).

This empirical research complements theoretical work (e.g. Hinterleitner \& Sager, 2016; Vis, 2016) on the blame avoidance strategies that are available to elected representatives looking to diffuse responsibility-including by manipulating procedures (see Pal \& Weaver, 2003). This work suggests that soliciting constituent opinion via a public consultation could be a promising tool for representatives trying to avoid blame (see MacCoun, 2005). Yet the scope of any such blame-avoidance effect, as well as the conditions under which it might operate, remain unclear. To date, most research examining the effect of procedure manipulation on blame attribution focuses on either (1) the effects of federalism or delegation to lower (e.g. municipalities) or higher (e.g. the European Union) government levels (Vis, 2016) or (2) reactive blame avoidance strategies-i.e. strategies adopted after the occurrence of blame (Sulitzeanu-Kenan \& Hood, 2005)—rather than anticipatory ones. ${ }^{1}$ Experimental work on blame avoidance is especially uncommon. Existing studies typically examine manipulating pay offs (rather than procedures) by focusing on

\footnotetext{
1 There is also a strand of literature focusing on blame games - a series of interactions between those who make and those who take blame over controversial political issues (Hood 2011). For instance, Hinterleitner (2020) examined how factors like the institutionalized accountability structure influence how blame games around policy controversies play out in diverse institutional contexts. But where we focus directly on the blame attribution patterns of citizens, Hinterleitner (2020) looks at how the public and blame game actors attribute or receive blame via the media.
} 
framing effects (e.g. Marx \& Schumacher, 2016; Wenzelburger \& Hörisch, 2016). There are two exceptions that, as in the present study, investigate procedure manipulation: Sulitzeanu-Kenan (2006), who finds that appointing a public inquiry does not necessarily decrease blame; and DeScioli and Bokemper (2014), who show that delegating a decision to a group vote can reduce blame. Where Sulitzeanu-Kenan (2006) focusses on a reactive strategy, DeScioli and Bokemper (2014), like us, examine an anticipatory strategy. Existing work has nonetheless never, to our knowledge, investigated either the impact of public consultations or the effect of gender and gender attitudes on blame attribution.

Yet public consultations offer an important case study in potential procedure manipulation. On the one hand, public consultations have been touted as a means to increase democratic quality, since consultations can improve democratic decisionmaking processes and bring policy-affected groups into the fold (e.g. Crompton, 2019; Kevins \& Robison, 2021); but by lengthening the causal decision path and potentially weakening clarity of responsibility, public consultations may diffuse perceived responsibility for a policy decision and, consequently, blame. On the other, research on procedural fairness suggests that under certain conditions, such an effect may even persist - both for consultation participants and the public at large-when policy decisions have not been adapted to align with constituent opinion (c.f. Esaiasson et al., 2019; Porumbescu \& Grimmelikhuijsen, 2018). The logic here is that the perceived "fairness" of decision-making procedures may act as a stand-in for letting citizens affect policy. If this is the case, the simple act of holding a consultationeven in the absence of visible constituent influence-might be enough to mitigate blame.

In designing our study, we thus build on past work on clarity of responsibility (e.g. Hobolt \& Tilley, 2014) and democratic responsiveness (e.g. Esaiasson et al., 2015). ${ }^{2}$ The proposed link between public consultations and blame avoidance, however, raises several unanswered questions. First, at present we are simply assuming that processes that lead individuals to be more accepting of a decision and to view representatives as more responsive to constituents will reduce blame-but we do not yet have evidence to that effect. Second, the blame-avoidance potential of public consultations may or may not rely on an alignment between the policy decision and constituent opinion (c.f. Esaiasson et al., 2017; Ulbig, 2008). Even when a policy goes against the public's will, it may be that representatives who listen to constituents and explain their stance on the issue can reduce blame attribution; such an effect would suggest that clarity of responsibility is not the key mechanism, since a consultation that offered constituents no clear room for input should not affect responsibility diffusion. Finally, and for related reasons, it is unclear how alignment might matter for blame attribution: will a consultation reduce blame attribution levels just so long as constituents do not actively oppose the proposed policy?; or must elected representatives clearly take into account the opinions expressed by

\footnotetext{
${ }^{2}$ OA4 also presents additional analysis looking at the relevance of the severity of the negative outcomes stemming from the decision (see Robbennolt 2000).
} 
consultation participants, revising their initial stance to actively align it with that of their constituents? These open questions generate the following hypotheses:

H1a: Respondents who accept the decision will attribute less blame to elected representatives.

H1b: Respondents will attribute less blame to elected representatives if they perceive the representative to be responsive.

H2a: Respondents will attribute less blame to elected representatives when the public consultation entailed representatives listening to constituents, explaining their stances, and aligning their policy with constituent preferences.

H2b: Respondents will attribute less blame to elected representatives when the public consultation entailed representatives listening to constituents and explaining their stances, even where the policy does not align with constituent preferences.

H3: Respondents will attribute less blame to elected representatives who actively aligned their policy with constituent preferences (i.e. the representative changes course to align the plan with constituent opinion) rather than simply being passively aligned with constituent preferences (i.e. the representative's initial plan already with constituent opinion). ${ }^{3}$

\section{Representative and Constituent Attributes}

Our first set of hypotheses focused on consultation characteristics. Alongside these factors, however, representative and constituent characteristics are likely to influence patterns of blame attribution as well. In the main analysis, we focus on the ways in which gender-related factors might condition the impact consultations have on blame attribution, as this analysis provides our most novel contribution to the existing literature on blame. In Online Appendix 4 (OA4), we also examine the relevance of a respondent's stance on the proposal (e.g. Esaiasson et al., 2019; Kevins, 2020) as well as their shared or contrasting partisanship with the legislator (e.g. Bisgaard, 2015; Malhotra \& Kuo, 2008).

A burgeoning literature has focused on the ways in which gender and gender attitudes shape how elected representatives are assessed by voters and constituents (e.g. Bauer, 2015; Bock et al., 2017; Simas, 2020); while research in social psychology, in turn, has examined the interplay of gender and blame in other contexts (e.g. Anderson \& Lyons, 2005; Parker et al., 2020; van der Bruggen \& Grubb, 2014). Yet we do not know whether-and under what conditions-gender influences how blame is attributed to elected representatives.

On the one hand, voters may have different expectations for the outreach and decision-making behaviour of male and female elected representatives: soliciting public feedback, for example, or imposing one's own stance on an issue, may be viewed

\footnotetext{
3 Though less theoretically interesting for our purposes, we also tested a related hypothesis to parse out the effects of a representative changing their stance versus that of changing their stance to align with the public: namely, that active non-alignment (i.e. the representative changes course to go against constituent opinion) will lead to greater blame attribution than passive non-alignment (i.e. the representative's initial plan goes against constituent opinion). We discuss the findings on this in the main text.
} 
differently depending on the politician's gender. Indeed, past research suggests that the public is more positively inclined toward stereotype-conforming behavior, with a more communicative (i.e. communal) model linked to females and a more assertive (i.e. agentic) one linked to males (e.g. Aaldering et al., 2020; Everitt et al., 2016). On the other, existing evidence suggests that voters may be broadly more critical of female politicians than of male ones (e.g. Anderson et al., 2011; Carey \& Lizotte, 2019; Fulton, 2014) — arguably because voters view politics as more "agentic" than "communal" (e.g. Eagly \& Karau, 2002; Koenig et al., 2011).

The most relevant existing research, however, examines the ways in which a politician's gender influences reactions to scandals: yet while some of these studies suggest that voters judge women more harshly than men, others find no real evidence of gender effects (c.f. Bhatti et al., 2013; Smith et al., 2005; Stewart et al., 2013). What is more, related experimental research looking at how gender differences may shape perceptions of corruption and patterns of accountability has come to especially mixed findings (Eggers et al., 2018; Pereira, 2020). These divergent results thus raise questions about the conditions under which voters may be more or less likely to attribute blame to male versus female representatives - and negative views on women are likely to play a key factor driving any such variation. The central concept here is "hostile sexism", traditionally defined as "an adversarial view of gender relations in which women are perceived as seeking to control men, whether through sexuality or feminist ideology" (Glick \& Fiske, 2001, p. 109). Defined in opposition to "benevolent sexism", ${ }_{4}^{4}$ hostile sexism is widely used to assess the impact of negative gender attitudes (see, for example, Barnes et al., 2020). It therefore offers the most promising route to investigating the impact of gender-related attitudes.

Drawing from existing literature (e.g. Carey \& Lizotte, 2019; Fulton, 2014; Stewart et al., 2013), our baseline hypothesis here is that, all else being equal, respondents will attribute more blame to a female elected representative than a male onein the process potentially gendering the effectiveness of public consultations as a blame avoidance strategy. Yet past research also suggests that gender-related effects are unlikely to be evenly distributed across voters, with hostile sexism being a strong candidate for explaining heterogeneity (e.g. Bock et al., 2017; Schaffner, 2020). Our main analysis thus further unpacks the relationship between public consultations and blame attribution, exploring potential variation in consultation effects via two final hypotheses on representative and constituent attributes:

H4a: Respondents will attribute more blame to female than male representatives.

H4b: The size of the gender effect on blame attribution will be moderated by hostile sexism.

\footnotetext{
${ }^{4}$ Benevolent sexism is typically associated with an "idealization of women [that] simultaneously implies that they are weak and best suited for conventional gender roles" (Glick and Fiske 2001).
} 


\section{Empirical Analysis}

We investigate these hypotheses using two nationally representative survey experiments. ${ }^{5}$ Study 1 provides an initial investigation into how public consultations and gender might shape blame attribution. Study 2 then adapts and improves the initial experiment, with the goal of better assessing the impact of gender-related attributes and policy adaptation to constituent opinion (Table 1).

\section{Study 1}

Study 1 uses a pre-registered ${ }^{6}$ survey experiment fielded with Lucid in September/ October 2019 to investigate how blame attribution is shaped by: decision acceptance (H1a) and perceived responsiveness (H1b); representatives listening to constituents, explaining their stances, and either aligning (H2a) or not aligning their policy with constituent opinion ( $\mathrm{H} 2 \mathrm{~b})$; the elected official's gender (H4a); and respondents' gender attitudes (H4b). Lucid's online panel has been shown to reasonably reproduce observational results from standard surveys (e.g. the American National Election Study) as well as experimental results from several seminal studies (Coppock $\&$ McClellan, 2019). The sample consists of 3200 US respondents, with quotas on gender, age bracket, and geographical region designed to reflect census data (see OA1 Table 1). The experiment employs a $3 \times 2 \times 2$ between-subjects design, with 12 conditions in total (described below). Experimental group sizes range from 263 to 274, and the full sample demographics are presented in OA1 Table 2.

We present respondents with a vignette describing a city council decision to cut funding for a homeless shelter-a decision that ultimately results in the death of two homeless people during a cold snap (see OA5 for the full survey experiment questionnaire). The experiment varies the consultation (none versus listen and explain versus listen, explain, and align) as well as the gender (male versus female) and partisanship (Democrat versus Republican) of the mayor pushing for the cuts.

Respondents are first presented with an introductory text, a vignette outlining the hypothetical case, and a question assessing the respondent's stance on the proposal. The introductory text adopts its wording from past survey experiments (Riccucci et al., 2014, 2018; Van Ryzin \& Lavena, 2013) and centres on a hypothetical town to avoid deception. The introduction informs respondents that they "will read some text and answer some questions about a hypothetical city named Middletown", asking them to "Please consider the following information carefully, and answer the questions as if you were a resident of Middletown." The vignette then continues:

Middletown is having budgetary problems, and its City Council has enacted a series of cuts.

\footnotetext{
${ }^{5}$ Data and replication code are available at https://doi.org/10.17028/rd.lboro.16628890.v1.

${ }^{6}$ See: https://osf.io/srtvj/?view_only=1b11f735cc214a6e82473fc4764860aa.
} 
As part of this "budgetary realignment", [Kevin / Karen] Bailey, the local [Democratic / Republican] mayor, has suggested that municipal funding for local homeless shelters must be cut by $20 \%$. Others, however, worry that this will put the homeless population at risk, especially during Middletown's cold winters. ${ }^{7}$

Respondents are then asked whether they think this would be "a good or bad policy to enact?", with answers ranging from 1 ("Very bad policy") to 3 ("Neither good nor bad") to 5 ("Very good policy").

On the next page of the experiment, respondents are presented with one of the following consultation treatments, with the wording once again adapted from related research (Esaiasson et al., 2017):

Control: Without a significant public debate, [Kevin / Karen] Bailey decides to push forward with [his / her] proposed $20 \%$ cut to shelter funding and the bill is passed in City Council.

Listen and Explain: [Kevin / Karen] Bailey decides to hold a town hall meeting to discuss the proposal. At the meeting, [he / she] hears out all of the attendees and explains [his / her] own stance on the issue. Although most citizens were opposed to the proposal, the Mayor decides to push forward with [his / her] proposed $20 \%$ cut to shelter funding and the bill is passed in City Council.

Listen, Explain, and Align: [Kevin / Karen] Bailey decides to hold a town hall meeting to discuss the proposal. At the meeting, [he / she] hears out all of the attendees and explains [his / her] own stance on the issue. With most citizens in favor of the proposal, the Mayor decides to push forward with [his / her] proposed $20 \%$ cut to shelter funding and the bill is passed in City Council.

Respondents then answer three standard questions on perceived responsiveness (Esaiasson et al., 2015), asking whether the representative had "found out about the wishes of citizens?," "explained their policy to citizens," and "tried to accommodate citizens' wishes." The same page also includes three standard decision acceptance items: "I am satisfied with the outcome of the vote"; "I trust the elected politicians who participated in the vote"; and "It is important to comply with the decision". Potential responses to these questions range from 1 ("strongly disagree") to 5 ("strongly agree"), and the item ordering is randomized for both perceived responsiveness and decision acceptance.

The final page of the vignette presents respondents with the potentially blameworthy consequences:

In the wake of these cuts, the number of beds for the homeless drops by almost a fifth, and many of the city's homeless end up sleeping on the streets. Over the winter, two homeless Middletowners, Greg Walsh and Emily Baker, are

\footnotetext{
7 The names Kevin and Karen Bailey were chosen as they have been used to examine gender effects on candidate assessments in a series of past experiments (e.g. Bauer et al., 2017).
} 
found frozen to death on the city's streets-Middletown's first homeless deaths from hypothermia in over a decade. ${ }^{8}$

We then measure blame attribution, our outcome. We ask respondents to indicate the extent to which they blame the mayor, local Democrats/Republicans, and the City Council for the negative consequences flowing from the budget cut. The questions read "How much blame do the following actors deserve for the drop in the number of shelter places?" and "How much blame do the following actors deserve for the two deaths by hypothermia?" The listed actors, in turn, are The Mayor, Democratic Council Members, Republican Council Members, and City Council, with responses ranging from 1 ("no blame at all") to 3 ("some blame") to 5 ("a great deal of blame"). ${ }^{9}$ The ordering of these two question sets (i.e. regarding the drop in shelter places and the deaths by hypothermia) are varied randomly.

The next survey page then presents two factual attention or manipulation check (FMC) questions, asking about the mayor's gender and partisanship. Kane and Barabas (2019) recommend FMCs as the preferred type of manipulation checks because, in contrast to common alternatives, there is little evidence that FMCs distort treatment effects. We also followed their advice to place an FMC immediately after the outcome measure (Kane \& Barabas, 2019).

The vignette design is driven by several considerations: it is a reasonably realistic scenario ${ }^{10}$ that can be situated at the municipal level (and is thus closer to respondents); the varying severity of the negative outcomes can straightforwardly be incorporated via the two components of the outcome, with a direct causal chain to both consequences; and the scenario allows us to assess a serious, indisputably negative consequence (i.e. death) to minimize variation in interpretations of the outcome.

Finally, to examine the potential role of gender attitudes, we follow past work (e.g. Barnes et al., 2020; Glick \& Fiske, 1996; Schaffner, 2020) and examine hostile sexism using four items: "Women are too easily offended"; "Many women are actually seeking special favors, such as hiring policies that favor them over men, under the guise of asking for "equality"; "Women seek to gain power by getting control over men"; and "When women lose to men in a fair competition, they typically complain about being discriminated against". Response options range from 1 ("strongly disagree") to 5 ("strongly agree"). These questions are asked on the final survey page to avoid drop-offs (given the harsh tone of the items), while also placing

\footnotetext{
8 The names Greg Walsh and Emily Baker were chosen to minimize variation in racial ascriptions - with both names used in past experimental work to designate White individuals (e.g. Bertrand and Mullainathan 2004).

9 Note that we exclude the option to assign blame to citizens who attended the consultation, since: (1) this would not be possible for the control group; and (2) including an additional blame target for the noncontrol groups might in and of itself alter the distribution of blame.

10 See, for example: https://www.sacbee.com/news/local/article121763488.html; https://www.thelundrep ort.org/content/part-i-our-frozen-dead-hypothermic-'domicile-unknown'-deaths; https:/www.washington times.com/news/2018/oct/23/homeless-advocates-say-districts-winter-shelter-pl/; https://cincinnati.com/ story/news/2017/12/27/homeless-advocates-blame-cold-lack-city-facility-mans-death/983745001/. Note also that the problem is not simply limited to colder states (e.g. https://ktla.com/2019/02/17/more-homel ess-people-died-of-cold-weather-in-1-a-than-in-new-york-in-2018/).
} 


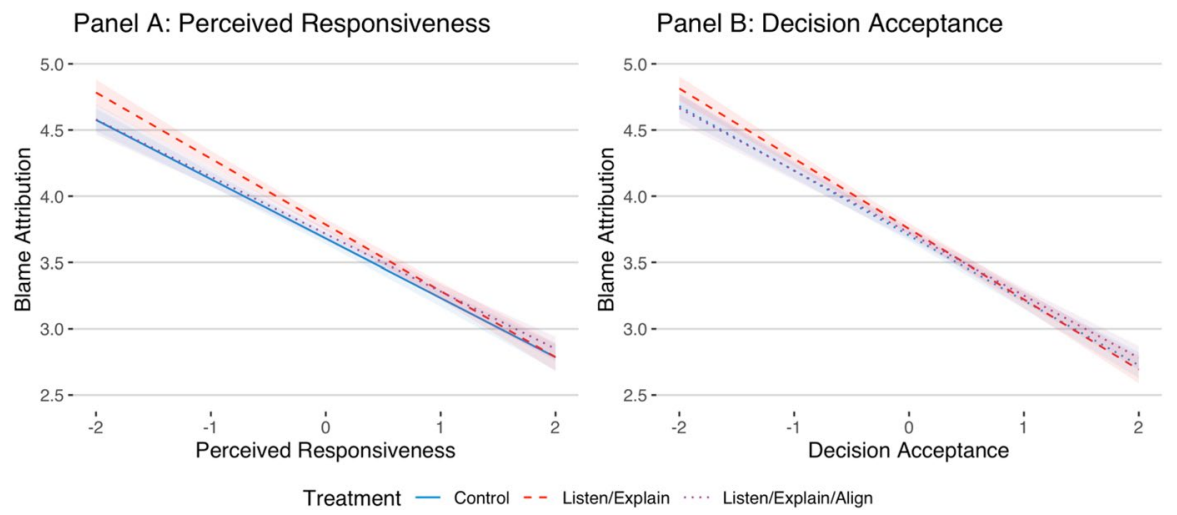

Fig. 1 Study 1 -effects of perceived responsiveness and decision acceptance on blame attribution

maximum space between the experiment and the battery. Immediately prior to these questions, we also collect demographic data and data on respondent partisanship using the standard American National Election Studies items to capture general identification, the distinction between strong and weak identifiers, and the difference between "true" independents and leaners. OA1 Table 3 presents descriptives of all key variables.

\section{Results}

We conduct our analyses using ordinary least squares (OLS) regressions, using the average of the two blame attribution questions vis-à-vis the mayor as our main dependent variable (Eigenvalue $=1.75$, factor loading $=0.94$, proportion of variance explained $=0.88$ ). We illustrate results via figures, with regression tables reported in OA2 Tables 1 and 2. All figures show mean responses with 83.5 percent confidence intervals, such that a lack of overlapping confidence intervals indicates statistical significance at the $p<0.05$ level (see Bolsen \& Thornton, 2014). Coefficients and levels of statistical significance (indicating differences relative to the corresponding control group) are also included where appropriate. As there is no evidence to suggest that random assignment was not effective, we exclude controls from the models (Mutz et al., 2017).

We begin by considering whether we find the expected relationship between, on the one hand, blame attribution and, on the other, decision acceptance and perceived responsiveness. If the theoretical link we draw between blame attribution and process preferences is correct, we should find that blame levels decrease as decision acceptance and perceived responsiveness increase. Results (see Fig. 1) display the expected patterns: whether in the control group or either of the two consultation treatments, respondents assigned lower blame, on average, when they expressed higher decision acceptance (supporting H1a) and perceived responsiveness (supporting $\mathrm{H} 1 \mathrm{~b})$. 
Panel A: Overall Effects

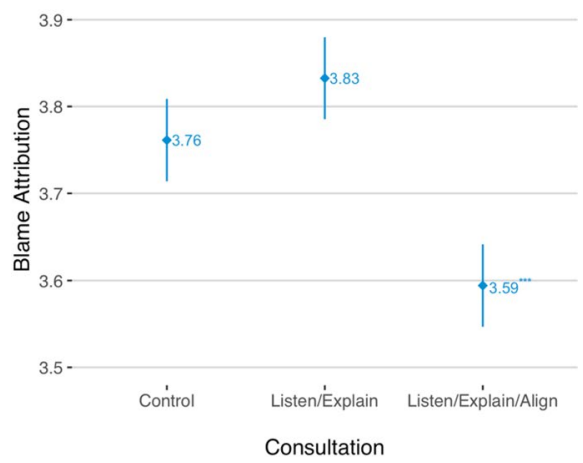

Panel B: Gender Effects

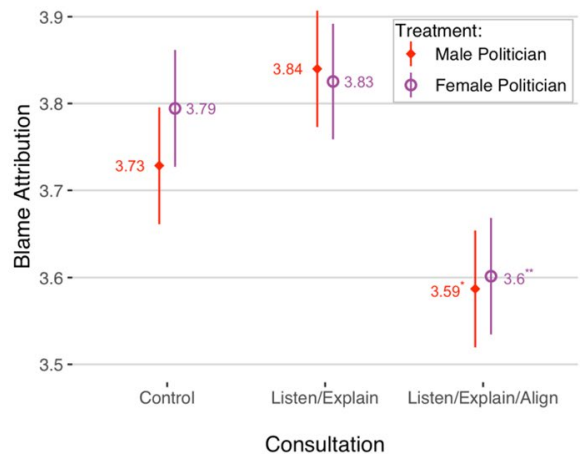

Fig. 2 Study 1 -predicted values of blame attribution, overall effects and by mayor's gender

Figure 2 then considers consultation and gender effects. Panel A indicates that respondents attributed lower levels of blame when the mayor listened, explained, and aligned their position with the majority (supporting H2a). Relative to the control group, we note a decrease in blame of 0.17 (SD: 1.12). We find no evidence of such an effect, however, when the mayor's position did not align with the majority (contra H2b). Panel B, in turn, illustrates that the mayor's gender does not seem to affect blame attribution (contra $\mathrm{H} 4 \mathrm{a}$ ). This is true even if we narrow our sample to respondents who correctly recalled the mayor's gender (67\% of respondents; we return to this point below). Similarly, results looking at the potential impact of hostile sexism (see Fig. 3) do not reflect the hypothesised impact of gender-related attitudes, since hostile sexism is associated with reduced blame regardless of the representative's gender. Supplementary analysis suggests that this is partly explained by a strong correlation between hostile sexism and conservatism-but the effect persists even when controlling for ideology, and is present among both Democrats and Republicans.

\section{Study 1 Limitations}

Study 1 provides some initial insights on whether and how public consultations can help elected representatives to avoid blame-but three limitations are particularly noteworthy. First, the effects of gender attitudes may be underestimated due to the relatively high proportion of respondents who could not correctly recall the mayor's gender immediately after the experiment (just under one third). Regardless of whether this reflects issues with the Lucid panel or with the vignette design, Study 2 (fielded via Qualtrics) takes steps to address the possible underestimation of genderrelated effects. Second, given the partisan nature of the policy issue, the effects of gender attitudes may be obscured by overlap between respondent stance and ideology. Finally, the setup of Study 1 only allowed us to assess the impact of passive, not active, alignment-making it difficult to distinguish the effects of public 

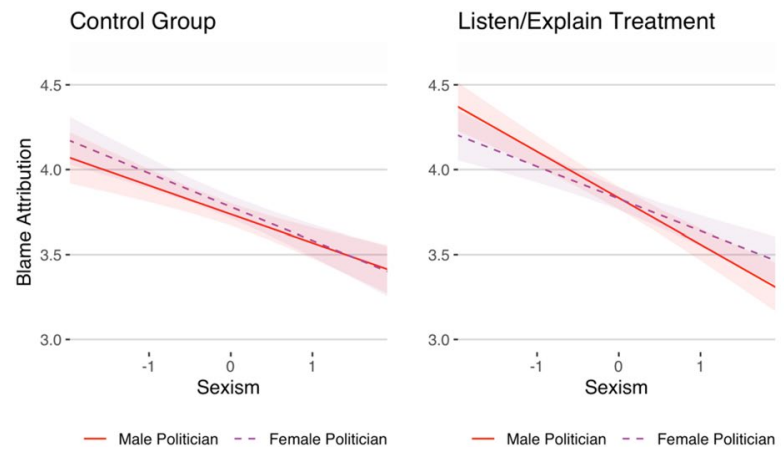

Fig. 3 Study 1-predicted values of blame attribution across hostile sexism, by mayor's gender and treatment group

consultations from the effects of aligning (or failing to align) the policy decision with constituent opinion. It may be that incidental alignment (i.e. participants at the public consultation happen to agree with the mayor's plan) and active alignment (i.e. the mayor changes course to align their plan with participant opinion) have fundamentally different consequences for blame attribution; yet Study 1's design prevents us from being able to unpack these potential differences.

\section{Study 2}

Study 2 uses a second pre-registered survey experiment ${ }^{11}$ fielded to 2,299 Americans via Qualtrics in November/December 2019-again using quota samples on gender, age bracket, and region to reflect census data. Full sample demographics are laid out in OA1 Table 2. There are 12 conditions in total, varying the consultation type (none versus listen, explain, and unaligned versus listen, explain, and align), the policy decision (pursue initial plan versus change course), and the mayor's gender (male versus female). Experimental group sizes range from 189 to 192.

The setup of Study 2 largely replicates that of Study 1, but with a few key changes to address the limitations highlighted above. First, we increased the number of gender cues (e.g. he/she, her/his). Second, we focus on a less ideologically coloured policy decision-flood damage prevention-to reduce potential confounding effects tied to partisanship; given likely overlap between conservatism and gender attitudes, this helps us to parse gender-related considerations from broader ideological ones. Third and relatedly, we include two policy options (that nevertheless result in the same blameworthy events) to generate conditions with active and passive (dis-) alignment. These new conditions replace the partisanship treatments to maintain sufficient power.

${ }^{11}$ See: https://osf.io/9unme/?view_only=423172237f88472a8dfa1ebe260931c3. 
In drawing up the experiment (see OA6 for the full survey experiment questionnaire), we adapted the scenario wording from DeScioli and Bokemper (2014), who provide the closest study to our own. After the same introductory text used in Study 1, the first component of the vignette reads as follows (for simplicity, we present only the text for the variant where the mayor is a woman):

Karen Bailey is the Mayor of Middletown. Her job is to make important decisions for the community.

Karen Bailey is deciding how to protect the town from flood waters caused by an impending storm. She wants to reinforce a wall along the river bank, but some people think the town should reinforce the levee instead. The town doesn't have the time and resources needed to do both.

Respondent stance is then recorded via a question asking what respondents "think would be the better course of action": "reinforce the wall"; "reinforce the levee"; and "don't know".

The consultation texts then broadly replicate those from Study 1 -but they also underline whether the mayor's (dis-)alignment with public opinion was passive or active. Concretely, this means that the mayor decides either to push forward with her plan and reinforce the wall or to change course and reinforce the levee instead. Note that this also requires additional variation in the control (i.e. no consultation) condition, so as to correspondingly vary the policy decision. The treatments in Study 2 read as follows:

Control: Without a significant public debate, Karen Bailey decides to [push forward with her plan to reinforce the wall / change course and reinforce the levee].

Listen and Explain: Karen Bailey holds an emergency town hall meeting to discuss her plan. At the meeting, she hears out all of the attendees and explains her own stance on the issue. Although most citizens wanted her to [change course and reinforce the levee / push forward with her plan to reinforce the wall], the Mayor decides to [push forward with her plan to reinforce the wall / change course and reinforce the levee].

Listen, Explain, and Align: Karen Bailey holds an emergency town hall meeting to discuss her proposal. At the meeting, she hears out all of the attendees and explains her own stance on the issue. [With most citizens in favor of reinforcing the wall, the Mayor decides to push forward with her plan / With most citizens in favor of changing course, the Mayor decides to abandon her plan and reinforce the levee].

As with Study 1, respondents are then asked the three standard items on perceived responsiveness described above. The decision acceptance items, in turn, are tweaked slightly to reflect the fact that the decision was taken unilaterally by the mayor. The questions thus read as follows: "I agree with the decision to reinforce the [wall / levee]"; "I trust the Mayor of Middletown"; and "It is important to comply with the Mayor's decision". 
Finally, the potentially blame-worthy consequences are described on the next page:

After the meeting, the Mayor puts the plan into action and the [wall / levee] is successfully reinforced. When the storm arrives, however, the flood waters break through the [levee / wall]. Much of the town is destroyed, and two Middletowners end up losing their lives.

Respondents are then asked how much blame the mayor deserves for "the town's destruction" and "the two deaths" (i.e. the blame attribution questions). As in Study 1 , these items are presented in randomized order, and potential responses range from "No blame at all" (1) to "A great deal of blame" (5). The next survey page then checks whether respondents correctly recall the mayor's gender, while the final survey page (separated from Study 2 by another experiment and several pages of demographic questions) presents the hostile sexism items. OA1 Table 3 provides detailed descriptives of all key variables.

\section{Results}

Our analysis of Study 2 follows the same approach used for Study 1, with OLS regression results listed in OA2 Tables 3 and 4. Here again we use the average of the two blame attribution questions vis-à-vis the mayor as the main dependent variable (Eigenvalue $=1.76$, factor loading $=0.94$, proportion of variance explained $=0.88$ ).

We begin by noting continued support for the relationship between, on the one hand, levels of blame attribution, and on the other, levels of decision acceptance and perceived responsiveness: OA3 Fig. 1 suggests that both decision acceptance (as per $\mathrm{H} 1 \mathrm{a})$ and perceived responsiveness (as per $\mathrm{H} 1 \mathrm{~b}$ ) are associated with reduced blame. Results from Study 2 also replicate other findings from Study 1: OA3 Fig. 2 supports $\mathrm{H} 2 \mathrm{a}$, with the "Listen, Explain, and Align" treatment associated with lower blame attribution (difference relative to control $=0.28 ; \mathrm{SD}=1.13$ ); while the same figure suggests no support for $\mathrm{H} 2 \mathrm{~b}$, since the "Listen and Explain" treatment appears, if anything, to increase blame attribution rather than reduce it (though this effect only nears statistical significance).

Turning to Study 2's novel components, we begin by considering if it matters whether elected representatives actively or passively align their stance with constituent opinion (H3). Figure 4's Panel A highlights that respondents tended to ascribe less blame to representatives who changed course and moved away from their original stance (i.e. reinforcing the wall), regardless of whether or not they consulted the population. ${ }^{12}$ This supports H3-but given shifting blame attribution in the control group as well, some caution is warranted here. We note that the "listen, explain, and align" treatment was also associated with reduced blame, both where the alignment was active (i.e. the mayor adapted her stance to align with the population) and

\footnotetext{
12 Adding controls for outcome favourability and the initial stance of the respondent (i.e. their preference for reinforcing the wall versus the levee) does not meaningfully affect results.
} 

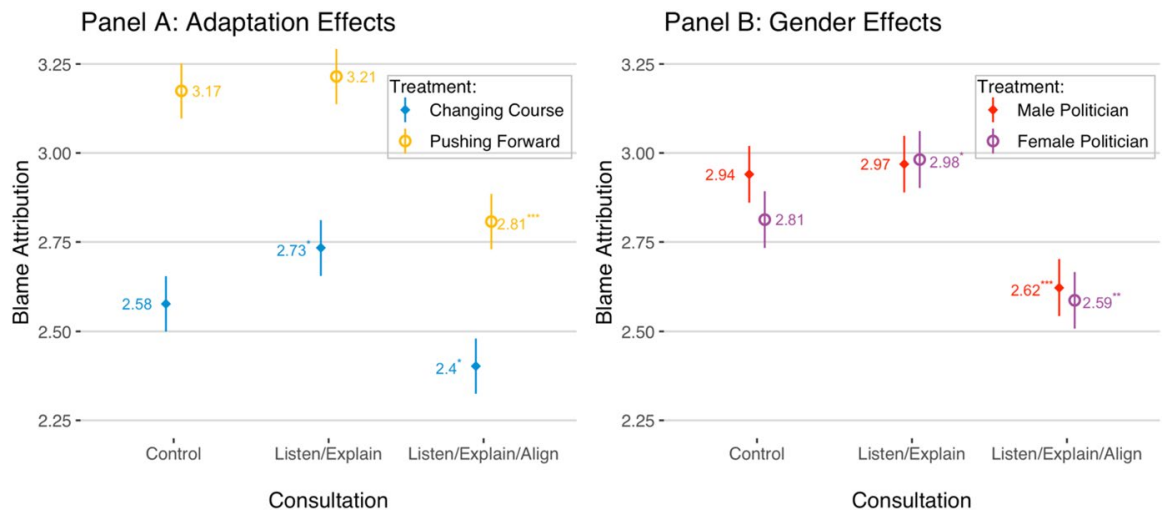

Fig. 4 Study 2-Predicted Values of Blame Attribution, by (Non-)Adaptation and Mayor's Gender

passive (i.e. the mayor's stance happened to align with majority opinion); the size of the effect, however, is twice as large in the Pushing Forward treatment $(0.36)$ than in the Changing Course one (0.18). We find even greater variation where the representative's decision did not align with constituent opinion: within the "listen and explain" treatment group, active dis-alignment (i.e. changing course where the population was supportive of the mayor's initial stance) engendered greater blame relative to the control (difference relative to control $=0.15$ ), whereas we find no effect in cases of passive dis-alignment (i.e. staying course even though the population disagrees with the mayor's stance). We unpack these results further in the conclusion.

As for the gender analysis, Fig. 4's Panel B reveals that Study 2 still finds no evidence that blame attribution increases when the mayor is a woman rather than a man (contra H4a). We do see more widespread consultation effects when the mayor is female, as the "Listen and Explain" treatment (i.e. consultation without alignment) increases blame relative to the control (difference relative to the control $=0.17$ ); yet while this relationship is absent when the mayor is male, the gender effect reflects a modestly higher level of blame for male representatives in the control. Similarly, Study 2 does not indicate any connection between hostile sexism and blame attribution (see OA3 Fig. 3). This suggests that even with a higher recall rate (78.5\% correctly remembered the mayor's gender in Study 2, versus 67.0\% in Study 1), gender attitudes are not shaping blame attribution in the hypothesized manner. Indeed, exploratory results looking exclusively at respondents who correctly answered the gender check question confirm this pattern, with only one exception: for this attentive subsample, hostile sexism did increase the blame attributed to the female mayor in the "Listened, Explained, and Aligned" treatment—an effect that was absent when the mayor was male. 


\section{Discussion}

This article has drawn together insights from the literatures on clarity of responsibility, procedural fairness, and blame attribution to explore whether public consultations can help elected representatives to avoid being blamed for decisions that end up backfiring. In carrying out this investigation, we also built on a long line of research on the effects of gender-related characteristics to examine the potential conditioning impact of these factors on patterns of blame attribution. (The Online Appendix, in turn, considers additional factors such as partisanship and respondent preferences.)

The analysis is based on two pre-registered survey experiments conducted on nationally representative samples of US respondents, seeking to examine: (1) the effect of consultation characteristics - specifically, whether elected representatives aligned their policy with constituent opinion, and whether this alignment was active or passive; and (2) representative and respondent characteristics-specifically the representative's gender and a respondents' gender attitudes. Study 1 centred on a partisan issue-homeless shelter funding - and was fielded by Lucid $(n=3200)$. Study 2, building on findings from Study 1, centred on a non-partisan issue-flood damage prevention-and was fielded by Qualtrics $(n=2299)$. Table 1 summarizes the main findings and hypotheses.

Results suggest that perceived responsiveness and decision acceptance reduced blame as expected (supporting H1a and H1b). Furthermore, respondents assigned lower levels of blame when the mayor aligned their position with the majority (supporting $\mathrm{H} 2 \mathrm{a}$ ), but not when he or she did not (contra $\mathrm{H} 2 \mathrm{~b}$ ). Results therefore highlight that alignment is a necessary ingredient for blame reduction, which suggests that reduced clarity of responsibility may be key to these effects.

Study 2 then allowed us to disentangle the effect of active versus passive alignment/non-alignment. Results indicate that respondents tended to ascribe less blame when the mayor moved away from his or her original stance-thus supporting H3 and the importance of clarity of responsibility. We are hesitant to draw strong conclusions on $\mathrm{H} 3$, however, given the broader shift in recorded blame attribution across treatment groups where the representative changed course. While future research is needed to unpack this finding, it may reflect the fact the vignette's introduction mentions latent opposition to the mayor's plan: in the face of this broader disagreement, the simple act of changing course may have decreased clarity of responsibility by suggesting the mayor's openness to taking alternative viewpoints on board.

Moreover, we found that the "listen, explain, and align" treatment was associated with reduced blame, both where alignment was active and passive. This provides additional evidence for $\mathrm{H} 2 \mathrm{a}$. When the mayor's policy did not align with constituent opinion, we found greater variation: active dis-alignment (i.e. changing course where most participants supported the initial stance) was tied to greater blame relative to the control, whereas we find no effect in cases of passive dis-alignment (i.e. staying course even though most participants disagreed with the mayor's stance). This makes intuitive sense, since active dis-alignment suggests a larger breach of democratic responsiveness than passive dis-alignment; it would also, if anything, 


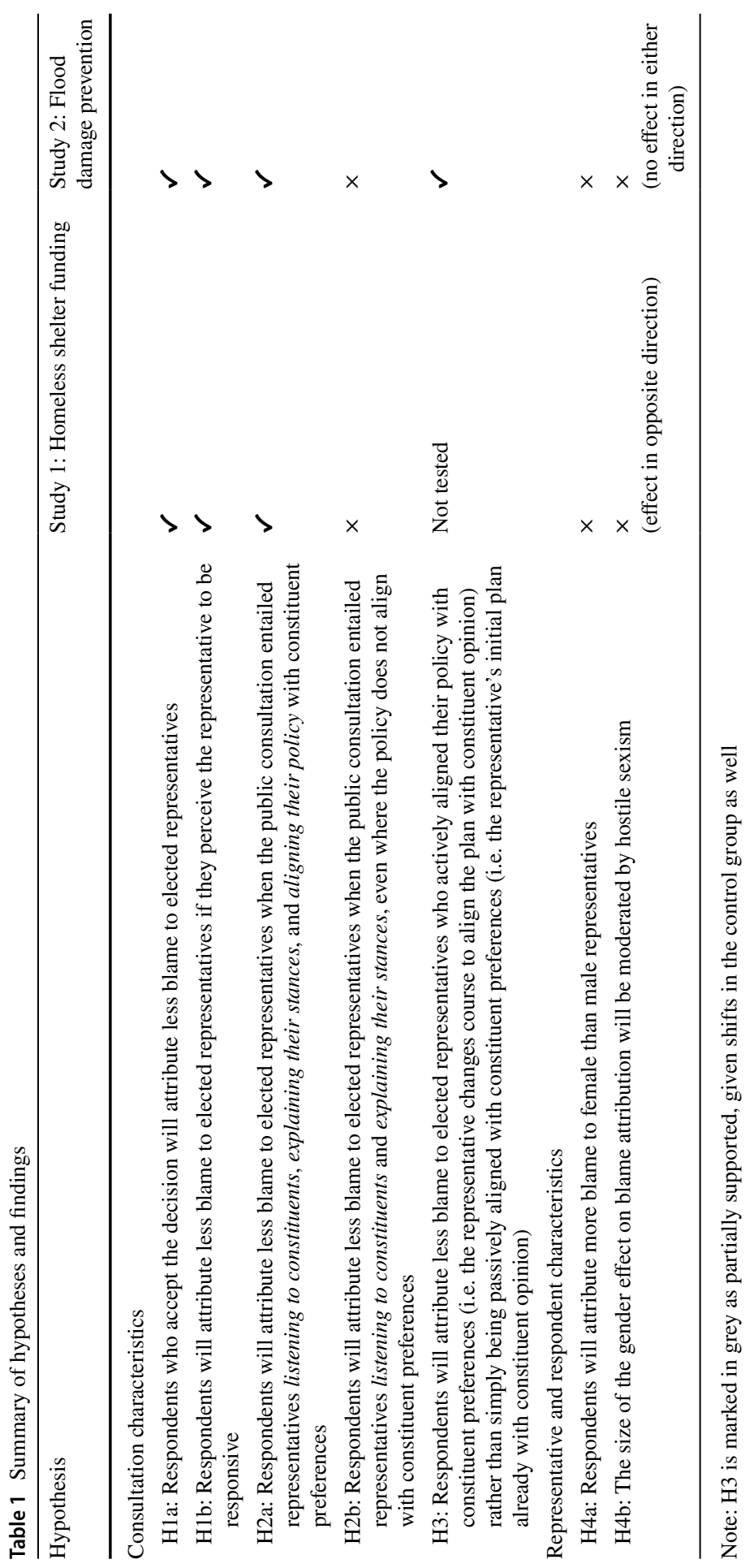


increase clarity of responsibility by underscoring the mayor's dominant role in the decision-making process.

Finally, neither Study 1 nor Study 2 found an effect of the mayor's gender in and of itself (contrary to H4a). Study 2, however, did point to more widespread consultation effects when the mayor was a woman, as the "Listen and Explain" treatment increased blame attribution (relative to the control) for the female mayor, but not the male one. As for respondents' gender attitudes, Study 1 suggested that hostile sexism was associated with less blame regardless of the representative's gender (contra H4b); yet this was arguably driven by an overlap between gender attitudes and ideology — an interpretation that seems especially plausible given that Study 2, which centred on a non-partisan issue, found no evidence of such an effect. Furthermore, exploratory analysis conducted only on Study 2 respondents who correctly recalled the mayor's gender did uncover modest evidence of the expected gender-attitude effect: in this sub-sample, hostile sexism was associated with increased blame attributed to the female mayor in the "Listened, Explained, and Aligned" treatment—an effect that was absent when the mayor was male.

Overall, the studies presented here support the claim that public consultations can, under certain circumstances, reduce blame attribution - thereby helping elected representatives to avoid being blamed for decisions that end up backfiring. Importantly, this suggests that the same consultation measures that are lauded for their potential to improve democratic quality (e.g. Crompton, 2019; Kevins \& Robison, 2021) might also serve as an effective blame avoidance strategy. The fact that these dynamics appear to play out similarly regardless of the elected representative's gender and the respondents' gender attitudes is also striking. Results thus broadly align with work suggesting that gender-related attributes may have weaker effects on reactions to scandals and controversies than is sometimes assumed (e.g. Bhatti et al., 2013; Eggers et al., 2018).

Several caveats are nevertheless in order, and point to potentially fruitful avenues for future research. First, the lack of gender effects might be linked to the strength of the treatment: despite the additional cues added in Study 2, it may be that names and pronouns are simply not strong enough gender markers. Further research incorporating visual cues (e.g. Crowder-Meyer et al., 2020) would thus help to assess the robustness of this finding. Second, we posited that the at-times counterintuitive effect of hostile sexism might reflect the measure's connection with conservatism; it could instead, however, be driven by the measure's connection to benevolent sexism (see Glick \& Fiske, 1996) — but we lack the data required to assess this possibility. Lastly, our survey experiments were designed to produce novel insights on blame attribution, responding to previous calls (e.g. Wenzelburger \& Hörisch, 2016) to conduct more research on the impact of different blame avoidance strategies. Yet this approach also means that our two studies are bound by the limits of experimental vignettes (see, for example, Gaines et al., 2007): respondents are cast as simple bystanders in the situation; the decision-consequence sequence is presented in a stylized manner, with causes and consequences separated by a single survey page, rather than (potentially) occurring months apart; and respondents are given only a single framing of the events. Future work testing the external validity of the findings 
would therefore be especially valuable - investigating, for example, how the presence of competing explanatory frames might shape the link between consultations and blame attribution in the real world (see Robison, 2021).

Supplementary Information The online version contains supplementary material available at https://doi. org/10.1007/s11109-021-09751-5.

Acknowledgements This research was funded by the European Commission's Horizon 2020 Programme via a Marie Skłodowska-Curie Individual Fellowship (Grant no. 750556). The paper also benefited from feedback provided at the University of Amsterdam Hot Politics Lab, the Utrecht University School of Governance, the 2019 Annual Meeting of the Dutch and Flemish Political Science Associations, and the 2021 American Politics Group Annual Conference. We would also like to thank Loes Aaldering, Marija Aleksovska, Tom Overmans, Gijs Schumacher, Laura Skillen, Mariken van der Velden, Kees van Kersbergen, the Editors at Political Behavior, and the anonymous reviewers for their helpful comments.

Funding Horizon 2020 Programme (European Commission), Marie Skłodowska-Curie Individual Fellowship (Grant no. 750556).

Data Availability Available at https://doi.org/10.17028/rd.lboro.16628890.v1.

Code availability Available at https://doi.org/10.17028/rd.lboro.16628890.v1.

\section{Declarations}

Conflicts of interest The authors declare that they have no conflict of interest.

Open Access This article is licensed under a Creative Commons Attribution 4.0 International License, which permits use, sharing, adaptation, distribution and reproduction in any medium or format, as long as you give appropriate credit to the original author(s) and the source, provide a link to the Creative Commons licence, and indicate if changes were made. The images or other third party material in this article are included in the article's Creative Commons licence, unless indicated otherwise in a credit line to the material. If material is not included in the article's Creative Commons licence and your intended use is not permitted by statutory regulation or exceeds the permitted use, you will need to obtain permission directly from the copyright holder. To view a copy of this licence, visit http://creativecommons.org/licen ses/by/4.0/.

\section{References}

Aaldering, L., Pas, D. J., \& Vander. . (2020). Political Leadership in the Media: Gender Bias in leader stereotypes during campaign and routine times. British Journal of Political Science, 50(3), 911-931.

Anderson, C. J. (2007). The end of economic voting? Contingency dilemmas and the limits of democratic accountability. Annual Review of Political Science, 10, 271-296.

Anderson, I., \& Lyons, A. (2005). The effect of victims' social support on attributions of blame in female and male rape. Journal of Applied Social Psychology, 35(7), 1400-1417.

Anderson, M. R., Lewis, C. J., \& Baird, C. L. (2011). Punishment or reward? An experiment on the effects of sex and gender issues on candidate choice. Journal of Women, Politics \& Policy, 32(2), $136-157$.

Barnes, T. D., Beaulieu, E., \& Saxton, G. W. (2020). Sex and corruption: How sexism shapes voters' responses to scandal. Politics, Groups, and Identities, 8(1), 103-121.

Bauer, N. M. (2015). Who stereotypes female candidates? Identifying individual differences in feminine stereotype reliance. Politics, Groups, and Identities, 3(21), 94-110. 
Bauer, N. M., Yong, L. H., \& Krupnikov, Y. (2017). Who is punished? conditions affecting voter evaluations of legislators who do not compromise. Political Behavior, 39(2), 279-300.

Bertrand, M., \& Mullainathan, S. (2004). Are emily and greg more employable than lakisha and jamal? a field experiment on labor market discrimination. American Economic Review, 94(4), 991-1013.

Bhatti, Y., Hansen, K. M., \& Leth Olsen, A. (2013). Political hypocrisy: The effect of political scandals on candidate evaluations. Acta Politica, 48(4), 408-428.

Bisgaard, M. (2015). Bias will find a way: Economic perceptions, attributions of blame, and partisanmotivated reasoning during crisis. The Journal of Politics, 77(3), 849-860.

Bock, J., Byrd-Craven, J., \& Burkley, M. (2017). The role of sexism in voting in the 2016 presidential election. Personality and Individual Differences, 119, 189-193.

Bolsen, T., \& Thornton, J. R. (2014). Overlapping confidence intervals and null hypothesis testing. The Experimental Political Scientist, 4(1), 12-16.

Carey, T. E. J., \& Lizotte, M.-K. (2019). Political experience and the intersection between race and gender. Politics, Groups, and Identities, 7(2), 243-266.

Coppock, A., \& McClellan, O. A. (2019). Validating the demographic, political, psychological, and experimental results obtained from a new source of online survey respondents. Research \& Politics. https://doi.org/10.1177/2053168018822174.

Crompton, A. (2019). Inside co-production: Stakeholder meaning and situated practice. Social Policy \& Administration, 53(2), 219-232.

Crowder-Meyer, M., Gadarian, S. K., Trounstine, J., \& Vue, K. (2020). A different kind of disadvantage: candidate race, cognitive complexity, and voter choice. Political Behavior, 42, 509-530.

DeScioli, P., \& Bokemper, S. (2014). Voting as a counter-strategy in the blame game. Psychological Inquiry, 25(2), 206-214.

Eagly, A. H., \& Karau, S. J. (2002). Role congruity theory of prejudice toward female leaders. Psychological Review, 109(3), 573-598.

Eggers, A. C., Vivyan, N., \& Wagner, M. (2018). Corruption, accountability, and gender: Do female politicians face higher standards in public life? Journal of Politics, 80(1), 321-326.

Esaiasson, P., Gilljam, M., \& Persson, M. (2017). Responsiveness beyond policy satisfaction: Does it matter to citizens? Comparative Political Studies, 50(6), 739-765.

Esaiasson, P., Kölln, A.-K., \& Turper, S. (2015). External efficacy and perceived responsiveness-Similar but distinct concepts. International Journal of Public Opinion Research, 27(3), 432-445.

Esaiasson, P., Persson, M., Gilljam, M., \& Lindholm, T. (2019). Reconsidering the role of procedures for decision acceptance. British Journal of Political Science, 49(1), 291-314.

Everitt, J., Best, L. A., \& Gaudet, D. (2016). Candidate gender, behavioral style, and willingness to vote: Support for female candidates depends on conformity to gender norms. American Behavioral Scientist, 60(14), 1737-1755.

Fulton, S. A. (2014). When gender matters: Macro-dynamics and micro-mechanisms. Political Behavior, $36(3), 605-630$.

Gaines, B. J., Kuklinski, J. H., \& Quirk, P. J. (2007). The logic of the survey experiment reexamined. Political Analysis, 15(1), 1-20.

Glick, P., \& Fiske, S. T. (1996). The Ambivalent Sexism Inventory: Differentiating hostile and benevolent sexism. Journal of Personality and Social Psychology, 70(3), 491-512.

Glick, P., \& Fiske, S. T. (2001). An ambivalent alliance: Hostile and benevolent sexism as complementary justifications for gender inequality. American Psychologist, 56(2), 109-118.

Hinterleitner, M. (2020). Policy controversies and political blame games. Cambridge University Press.

Hinterleitner, M., \& Sager, F. (2016). Anticipatory and reactive forms of blame avoidance: Of foxes and lions. European Political Science Review, 9(04), 587-606.

Hobolt, S. B., \& Tilley, J. (2014). Blaming Europe? Responsibility Without Accountability in the European Union. Oxford University Press.

Hobolt, S. B., Tilley, J., \& Banducci, S. (2013). Clarity of responsibility: How government cohesion conditions performance voting. European Journal of Political Research, 52(2), 164-187.

Hood, C. (2011). The Blame Game: Spin, Bureaucracy, and Self-Preservation in Government. Princeton University Press.

Kane, J. V., \& Barabas, J. (2019). No harm in checking: using factual manipulation checks to assess attentiveness in experiments. American Journal of Political Science, 63(1), 234-249.

Kevins, A. (2020). Input from Whom? Public reactions to consultation measures. Political Studies. https://doi.org/10.1177/0032321720956327 
Kevins, A., \& Robison, J. (2021). Who should get a say? race, law enforcement guidelines, and systems of representation. Political Psychology, 42(1), 71-91.

Koenig, A. M., Eagly, A. H., Mitchell, A. A., \& Ristikari, T. (2011). Are leader stereotypes masculine? A meta-analysis of three research paradigms. Psychological Bulletin, 137(4), 616-642.

MacCoun, R. J. (2005). Voice, control, and belonging: The double-edged sword of procedural fairness. Annual Review of Law and Social Science, 1(1), 171-201.

Malhotra, N., \& Kuo, A. G. (2008). Attributing blame: The public's response to hurricane katrina. The Journal of Politics, 70(1), 120-135.

Malle, B. F., Guglielmo, S., \& Monroe, A. E. (2014). A Theory of Blame. Psychological Inquiry, 25(2), 147-186.

Marx, P., \& Schumacher, G. (2016). The effect of economic change and elite framing on support for welfare state retrenchment: A survey experiment. Journal of European Social Policy, 26(1), 20-31.

Mutz, D. C., Pemantle, R., \& Pham, P. (2017). The perils of balance testing in experimental design: Messy analyses of clean data. American Statistician, 1305(November), 1-33.

Oktay, S. (2018). Clarity of responsibility and foreign policy performance voting. European Journal of Political Research, 57(3), 587-614.

Pal, L. A., \& Weaver, R. K. (2003). The government taketh away: The politics of pain in the United States and Canada. Georgetown University Press.

Parker, M. M., Mattson, R. E., Alexander, E. F., \& McKinnon, A. M. (2020). Does perceived injury explain the effects of gender on attributions of blame for intimate partner violence? A factorial vignette analysis. Journal of Family Violence. https://doi.org/10.1007/s10896-020-00229-2

Pereira, F. B. (2020). Do Female Politicians Face Stronger Backlash for Corruption Allegations ? Evidence from Survey - Experiments in Brazil and Mexico. Political Behavior. https://doi.org/10.1007/ s11109-020-09602-9.

Porumbescu, G. A., \& Grimmelikhuijsen, S. (2018). Linking decision-making procedures to decision acceptance and citizen voice: Evidence from two studies. The American Review of Public Administration, 48(8), 902-914.

Powell, G. B., Whitten, G. D., Powell, G. B., Jr., Whitten, G. D., Powell, G. B., \& Whitten, G. D. (1993). A cross-national analysis of economic voting: Taking account of the political context. American Journal of Political Science, 37(2), 391-414.

Riccucci, N. M., Van Ryzin, G. G., \& Jackson, K. (2018). Representative bureaucracy, race, and policing: A survey experiment. Journal of Public Administration Research and Theory, 28(4), 506-518.

Riccucci, N. M., Van Ryzin, G. G., \& Lavena, C. F. (2014). Representative bureaucracy in policing: Does it increase perceived legitimacy? Journal of Public Administration Research and Theory, 24(3), 537-551.

Robbennolt, J. K. (2000). Outcome severity and judgments of "responsibility": A meta-analytic review. Journal of Applied Social Psychology, 30(12), 2575-2609.

Robison, J. (2021). Can elites escape blame by explaining themselves suspicion and the limits of elite explanations. British Journal of Political Science. https://doi.org/10.1017/S000712342000071X

Schaffner, B. F. (2020). The heightened importance of racism and sexism in the 2018 US midterm elections. British Journal of Political Science. https://doi.org/10.1017/S0007123420000319

Simas, E. N. (2020). Extremely high quality? How ideology shapes perceptions of candidates' personal traits. Public Opinion Quarterly, 84(3), 699-724.

Smith, E. S., Smith Powers, A., \& Suarez, G. A. (2005). If bill clinton were a woman: the effectiveness of male and female politicians' account strategies following alleged transgressions. Political Psychology, 26(1), 115-134.

Stewart, D. D., Rose, R. P., Rosales, F. M., Rudney, P. D., Lehner, T. A., Miltich, G., et al. (2013). The value of outside support for male and female politicians involved in a political sex scandal. Journal of Social Psychology, 153(3), 375-394.

Sulitzeanu-Kenan, R., \& Hood, C. (2005). Blame avoidance with adjectives? Motivation, opportunity, activity and outcome. In ECPR Joint Sessions, Blame Avoidance and Blame Management Workshop, Granada, Spain, 14th-20th April.

Sulitzeanu-Kenan, R. (2006). If they get it right: An experimental test of the effects of the appointment and reports of UK public inquiries. Public Administration, 84(3), 623-653.

Ulbig, S. G. (2008). Voice is not enough. Public Opinion Quarterly, 72(3), 523-539.

van der Bruggen, M., \& Grubb, A. (2014). A review of the literature relating to rape victim blaming: An analysis of the impact of observer and victim characteristics on attribution of blame in rape cases. Aggression and Violent Behavior, 19(5), 523-531. 
Van Ryzin, G. G., \& Lavena, C. F. (2013). The credibility of government performance reporting. Public Performance \& Management Review, 37(1), 87-103.

Vis, B. (2016). Taking stock of the comparative literature on the role of blame avoidance strategies in social policy reform. Journal of Comparative Policy Analysis: Research and Practice, 18(2), 122-137.

Wenzelburger, G., \& Hörisch, F. (2016). Framing effects and comparative social policy reform: Comparing blame avoidance evidence from two experiments. Journal of Comparative Policy Analysis: Research and Practice, 18(2), 157-175.

Wlezien, C., \& Soroka, S. N. (2011). Federalism and public responsiveness to policy. Publius: the Journal of Federalism, 41(1), 31-52.

Wolff, P. (2003). Direct causation in the linguistic coding and individuation of causal events. Cognition, $88(1), 1-48$.

Publisher's Note Springer Nature remains neutral with regard to jurisdictional claims in published maps and institutional affiliations. 